\title{
Cross sectional Doppler echocardiography as the initial technique for the diagnosis of acute pulmonary embolism
}

\author{
E C Cheriex, N Sreeram, Y F J M Eussen, F A A Pieters, H J J Wellens
}

\begin{abstract}
Objective-To determine the value of cross sectional Doppler echocardiography and derived indices of right ventricular pressure and function in the initial diagnosis of pulmonary embolism.

Background-Most deaths from acute pulmonary embolism occur because of a delay in diagnosis. Ventilation-perfusion scans are not sufficiently sensitive, whereas angiography is invasive and associated with complications. The use of cross sectional Doppler echocardiography to assess acute changes in right ventricular filling pressure and function, and in pulmonary arterial systolic pressure and its relation to embolism has not been studied in a large population.
\end{abstract}

Methods- 60 consecutive patients with acute symptoms or haemodynamic instability suggestive of pulmonary embolism were studied. Confirmatory investigations included a ventilation-perfusion scan (36 patients), angiography (18 patients), surgery (5 patients), or necropsy (5 patients).

Results-There was evidence of right ventricular pressure or volume overload in all. This took the form of increased right ventricular end diastolic diameter and leftward bulging of the interventricular septum in diastole (56 patients); tricuspid valve regurgitation (56 patients) with the peak velocity of the regurgitant jet $>2.6 \mathrm{~m} / \mathrm{s}$; and a low collapse index for the inferior vena cava of $<40 \%$, indicating raised mean right atrial pressure (in 49 patients). Intracardiac or pulmonary thrombi were visualised in 10 patients. In 14 patients treatment was undertaken on the basis of the echocardiographic signs alone. Four of them (with visible thrombi) recovered: the other 10 died. Lung emboli were demonstrated in 4 of 5 patients in whom necropsy was performed.

Conclusions-Cross sectional Doppler echocardiography is a sensitive technique for the rapid identification of right ventricular overload in acute pulmonary embolism. It enables further investigations on treatment to be appropriately directed without delay. Resolution of emboli can also be assessed by serial measurement of the described indices.

(Br Heart f 1994;72:52-57)
Most deaths associated with pulmonary embolism occur because of delays in establishing the diagnosis and in starting appropriate therapy. Though most emboli originate from deep venous thromboses in the legs, most episodes of deep vein thrombosis are clinically silent. While investigations such as phlebography or impedance plethysmography may be directed towards ascertaining the presence of deep venous thromboses, confirmation of a pulmonary embolus depends on performing either a ventilation-perfusion scan or angiography. ${ }^{12}$ Previous studies have shown, however, that ventilation-perfusion scans are not always conclusive. ${ }^{3-5}$ Pulmonary arterial angiography is the definitive diagnostic test for pulmonary embolus. It is an expensive invasive procedure requiring specialised equipment and staff. Unless the possibility of pulmonary embolism is high, many pulmonary angiograms performed to demonstrate emboli may be normal. ${ }^{67}$ The $M$ mode and cross sectional echocardiographic features in patients with confirmed pulmonary embolism have been described elsewhere. ${ }^{8}$ With improved imaging techniques, the routine use of Doppler echocardiography, and a better understanding of the dynamics of systemic venous return to the right atrium, ${ }^{9}$ it is now possible to determine non-invasively the right ventricular systolic pressure ${ }^{10}$ and the response of the right ventricle to an acute pressure or volume overload. ${ }^{11}$ We used these techniques to detect right ventricular overload in a consecutive series of patients and determined their diagnostic value in pulmonary embolism.

Patients and methods

We studied 60 consecutive patients ( 35 male, 25 female) aged 44-86 years who were seen at the Academic Hospital Maastricht between November 1987 and December 1992 with acute onset or progressively worsening dyspnoea (49 patients), chest pain (eight patients), palpitation (one patient), or acute cardiovascular collapse (11 patients). None of the patients had a previous history of chronic lung disease, and surface electrocardiography during the acute episode did not show signs of a recent myocardial infarction. Five patients, however, had previously documented ischaemic heart disease with evidence of regional abnormalities of left ventricular wall motion on earlier echocardiography, while one patient had dilated cardiomyopathy 
without raised pulmonary arterial pressure.

Informed consent was obtained from all subjects before all investigations or treatments.

\section{ECHOCARDIOGRAPHY}

Cross sectional Doppler echocardiography was performed on a Hewlett Packard 77020 AC or Sonos 1000 ultrasound system with standard imaging transducers. In three patients with visible thrombi in the right atrium or ventricle single plane or biplane transoesophageal echocardiography $(5 \mathrm{MHz}$ transducer) was also performed. The internal diameter of the right ventricle at end diastole was measured from the cross sectional echocardiogram in the four chamber view. The right ventricular dimension was taken as the maximum distance between the endocardium of the right ventricular free wall and the interventricular septum at the level of the tips of the tricuspid valve leaflets, perpendicular to the long axis of the ventricle. The measurement was made at the onset of the $R$ wave of a simultaneously recorded electrocardiogram. We used this method because it was not possible consistently to delineate the anterior wall of the right ventricle on parasternal long axis echocardiograms because the anterior right ventricular free wall was too close to the transducer. This meant that much of the right ventricular cavity was undefinable. The average of three measurements was taken, and measurements were corrected to the nearest $0.5 \mathrm{~mm}$. All measurements were made by the same echocardiographer, either at the time of the initial assessment or from recorded videotape images. The motion of the interventricular septum during the cardiac cycle was assessed in short axis scans and was regarded as abnormal if the septum remained flattened or consistently bulged towards the left ventricle in diastole. ${ }^{11}$

From the subcostal scan position, with rightward angulation of the probe, the inferior vena cava was imaged in both its long and short axis. By image guided $M$ mode echocardiography both the widest diameter of this vessel during expiration and the smallest diameter during forced inspiration were measured. Measurements were taken during diastole before the $P$ wave of the electrocardiogram in the infradiaphragmatic portion of the vein just below its junction with the hepatic veins. A collapse index was then derived, defined as the change in diameter during respiration expressed as a percentage of the maximum diameter in expiration. ${ }^{1213}$ Studies controls and in patients with raised right atrial pressure showed that the normal collapse index is $>40 \%$, whereas a collapse index of $<40 \%$ correlated with a mean right atrial pressure of $>8 \mathrm{~mm} \mathrm{Hg}{ }^{12}{ }^{13}$

Finally, in all cases cross sectional image guided continuous wave Doppler echocardiography was performed from the subcostal, apical, or parasternal positions to detect the presence of tricuspid valve regurgitation and to measure accurately the peak systolic velocity of the regurgitant jet. The peak instantaneous transvalvar systolic gradient was then derived from the modified Bernoulli equation. ${ }^{10}$ In selected cases, tricuspid regurgitation was graded (1-4) from the colour Doppler flow image in the apical or parasternal four chamber view to reflect increasing severity according to the extension of the regurgitant jet into the right atrium and its density. ${ }^{14}$

\section{CORROBORATIVE INVESTIGATIONS \\ Ventilation-perfusion scan}

A standard ventilation-perfusion scan was performed in 36 patients. Perfusion studies were performed with intravenous injection of technetium-99m labelled macroaggregated albumin, in multiple projections, and xenon133 was inhaled for the ventilation studies. Scans were interpreted according to accepted criteria and were classified as normal or as showing a high, intermediate, or low probability of pulmonary embolism. ${ }^{16}$ Briefly, moderate and high probability scans showed subsegmental or segmental perfusion defects with normal ventilation (ventilation-perfusion mismatch) whereas low probability scans showed perfusion defects with a matching ventilation defect.

\section{Pulmonary arterial angiography}

Main or selective branch pulmonary arterial angiography using a non-ionic contrast agent with digital subtraction techniques was performed in 18 patients. Angiograms were regarded as positive for pulmonary emboli if there were unequivocal filling defects or cutoffs in the pulmonary arteries. The angiographic severity of embolism was graded according to the number of lung segments that showed filling defects and the degree of reduction in blood flow. ${ }^{17}$

\section{Results}

ECHOCARDIOGRAPHY

In acutely ill patients lying in the supine position the subcostal approach was particularly valuable not only in the evaluation of the diameters of the vena cava but also in assessing right ventricular function and tricuspid valve regurgitation.

\section{Tricuspid valve regurgitation}

Systolic pressure overload of the right ventricle was evident from the peak velocity of tricuspid regurgitation. This exceeded $3 \mathrm{~m} / \mathrm{s}$ (calculated peak instantaneous gradient across the tricuspid valve of $36 \mathrm{~mm} \mathrm{Hg}$ ) in 52 patients. In four others the peak velocities of tricuspid valve regurgitation were $2 \cdot 7 \mathrm{~m} / \mathrm{s}$ (two patients) and $2.8 \mathrm{~m} / \mathrm{s}$ (two patients) respectively, but all had grade 3 (three patients) or grade 4 (one patient) regurgitation by color Doppler flow imaging (table 1). Only four patients had no evidence of tricuspid valve regurgitation: three of them were in asystole and were undergoing resuscitation at the time of echocardiographic examination. Overall therefore, Doppler echocardiography provided a good index of acute pressure overload of the right ventricle in 56 of 57 patients who were in a spontaneous rhythm. 
Table 1 Echocardiographic data and other corroborative investigations in the patients studied

\begin{tabular}{|c|c|c|c|c|c|c|c|}
\hline No & $\begin{array}{l}\text { Tricuspid regurgitation } \\
\text { peak velocity }(\mathrm{m} / \mathrm{s})\end{array}$ & $R V E D D(\mathrm{~mm})$ & $R V$ dysfunction & $V C I<40 \%$ & Thrombus & $V / Q$ scan & Angiography \\
\hline 1 & None & 44 & Yes & No & RA & Yes & No \\
\hline 2 & $4 \cdot 2$ & 42 & Yes & Yes & - & Yes & No \\
\hline 3 & $3 \cdot 4$ & 33 & Yes & Yes & - & No & Yes \\
\hline 4 & $4 \cdot 1$ & 35 & Yes & Yes & - & Yes & No \\
\hline 5 & 3.5 & 37 & Yes & Yes & - & Yes & No \\
\hline 6 & $3 \cdot 5$ & $39 \cdot 5$ & Yes & Yes & - & Yes & Yes \\
\hline 7 & $3 \cdot 0$ & $40 \cdot 5$ & Yes & No & - & Yes & No \\
\hline 8 & $4 \cdot 0$ & 37 & Yes & Yes & - & Yes & No \\
\hline 9 & 3.9 & 40 & Yes & Yes & - & Yes (low probability)* & No \\
\hline 10 & $3 \cdot 7$ & $39 \cdot 5$ & Yes & No & - & No & Yes \\
\hline 11 & $4 \cdot 0$ & 45 & Yes & Yes & - & Yes & No \\
\hline 12 & $3 \cdot 2$ & 34 & Yes & Yes & - & Yes & No \\
\hline 13 & $2 \cdot 8 \dagger$ & 31 & Yes & Yes & - & No & Yes \\
\hline 14 & $3 \cdot 0$ & 46 & Yes & Yes & - & Yes & No \\
\hline 15 & $3 \cdot 0$ & 36 & Yes & Yes & - & No & Yes \\
\hline 16 & $3 \cdot 8$ & 45 & Yes & No & - & Yes & No \\
\hline 17 & $3 \cdot 8$ & 51 & Yes & Yes & - & No & Yes \\
\hline 18 & $3 \cdot 3$ & $37 \cdot 5$ & Yes & No & - & Yes & Yes \\
\hline 19 & $2 \cdot 8 \dagger$ & 29 & Yes & Yes & - & Yes & Yes \\
\hline 20 & $4 \cdot 0$ & 36 & Yes & Yes & - & Yes & No \\
\hline 21 & $3 \cdot 0$ & $44 \cdot 5$ & Yes & Yes & - & No & Yes \\
\hline 22 & $4 \cdot 3$ & 35 & Yes & Yes & - & Yes & Yes \\
\hline 23 & $3 \cdot 2$ & 52.5 & Yes & Yes & - & Yes & Yes \\
\hline 24 & $3 \cdot 1$ & 60 & Yes & Yes & - & No & Yes \\
\hline 25 & $3 \cdot 0$ & $36 \cdot 5$ & Yes & Yes & - & Yes & No \\
\hline 26 & $3 \cdot 3$ & 33 & Yes & Yes & - & Yes & No \\
\hline 27 & $3 \cdot 1$ & 30 & Yes & Yes & - & No & Yes \\
\hline 28 & $3 \cdot 2$ & 34 & Yes & Yes & - & Yes (low probability) & Yes \\
\hline 29 & $3 \cdot 2$ & $36 \cdot 5$ & Yes & Yes & - & Yes (low probability) & Yes \\
\hline 30 & $3 \cdot 8$ & 33 & Yes & Yes & - & Yes (low probability) & No \\
\hline 31 & $3 \cdot 8$ & $33 \cdot 5$ & Yes & Yes & RA & Yes & No \\
\hline 32 & $4 \cdot 3$ & $34 \cdot 5$ & Yes & Yes & - & Yes & No \\
\hline 33 & $3 \cdot 1$ & 35 & Yes & Yes & - & Yes & No \\
\hline 34 & $3 \cdot 1$ & $31 \cdot 5$ & Yes & Yes & - & Yes & No \\
\hline 35 & $3 \cdot 0$ & 39 & Yes & Yes & - & Yes & No \\
\hline 36 & $3 \cdot 2$ & 30 & Yes & Yes & - & Yes & No \\
\hline 37 & $3 \cdot 0$ & $53 \cdot 5$ & Yes & Yes & - & Yes & No \\
\hline 38 & $3 \cdot 2$ & $26 \cdot 5$ & Yes & Yes & - & Yes & No \\
\hline 39 & $3 \cdot 3$ & $38 \cdot 5$ & Yes & Yes & - & Yes & No \\
\hline 40 & $3 \cdot 0$ & 43 & Yes & Yes & RA & No & Yes \\
\hline 41 & $4 \cdot 0$ & 51 & Yes & Yes & - & Yes & Yes \\
\hline 42 & $3 \cdot 7$ & $39 \cdot 5$ & Yes & Yes & - & Yes & No \\
\hline 43 & $3 \cdot 2$ & 44 & Yes & Yes & - & Yes & No \\
\hline 44 & 3.5 & 40 & Yes & No & - & No & Yes \\
\hline 45 & $3 \cdot 2$ & 44 & Yes & Yes & - & Yes & No \\
\hline 46 & 3.5 & 51 & Yes & Yes & - & Yes & No \\
\hline
\end{tabular}

RA, right atrium; RVEDD, right ventricular end diastolic diameter (a normal RVEDD is < $27 \mathrm{~mm}$ ); VCI, collapse index of inferior vena cava V/O, ventilationperfusion scan. ${ }^{\star}$ Multiple emboli at necropsy; tgrade 3 or grade 4 regurgitation on Doppler colour flow imaging.

Collapse index of the inferior vena cava

The collapse index of the inferior vena cava was $<40 \%$ in 49 patients $(82 \%)$ in the acute stage. The collapse index was $<40 \%$ in all four patients in whom the measured peak velocity of tricuspid regurgitation was $<3 \mathrm{~m} / \mathrm{s}$ (table 1).

\section{Right ventricular dimensions and function}

In 56 patients the right ventricular end diastolic diameter $(28-60 \mathrm{~mm})$ exceeded the upper limit of normal for the adult popula$\operatorname{tion}^{818}$ (table 1). Diastolic dysfunction of the right ventricle was evident in 56 patients. This was characterised by paradoxical bulging of the interventricular septum towards the left ventricle in the four chamber view, suggesting a decreased diastolic pressure gradient across the ventricular septum. ${ }^{19}$

\section{Intracardiac or vascular thrombi}

Intracardiac or vascular thrombi were visualised in 10 patients: in the right atrium alone (seven patients), a right atrial thrombus extending into the left atrium through a patent foramen ovale (one patient), right atrium and ventricle (one patient), and right atrium and pulmonary arteries (one patient). Transoesophageal echocardiography was performed in three patients with a visible intracardiac thrombus: thrombi were detected in both branch pulmonary arteries in one patient.

\section{VENTILATION-PERFUSION SCAN AND}

ANGIOGRAPHY

The ventilation-perfusion scan indicated an intermediate or high probability of pulmonary embolus in 32 of 36 patients. This indicated a low probability of the thrombus in the remaining four patients. An embolus was confirmed at angiography in two of the four patients and at necropsy in another. In one patient who died in hospital no necropsy was performed.

An embolus was confirmed by pulmonary arterial angiography in all 18 patients in whom this examination was performed. The angiographic grade of severity ${ }^{17}$ ranged from 10 to 22 (median 15) (potential maximum score 34 ), and did not correspond with the right ventricular end diastolic diameter or the increase in pulmonary artery pressure as assessed by Doppler echocardiography, presumably because these investigations were performed under different haemodynamic states and not simultaneously.

\section{PATIENTS WITHOUT CORROBORATIVE}

\section{INVESTIGATIONS}

In 14 patients treatment was undertaken on the basis of the clinical and echocardiographic features alone (table 2). In seven cases, including three patients who had asystole and required cardiopulmonary resuscitation, intracardiac thrombi were visualised in the right atrium, ventricle, or pulmonary arteries. 
Table 2 Echocardiographic findings and outcome in patients without corroborative investigations for pulmonary embolus

\begin{tabular}{|c|c|c|c|c|c|c|c|}
\hline No & $\begin{array}{l}\text { Tricuspid regurgitation } \\
\text { peak velocity }(\mathrm{m} / \mathrm{s})\end{array}$ & $\begin{array}{l}\text { RVEDD } \\
(\mathrm{mm})\end{array}$ & $R V$ dysfunction & $V I C<40 \%$ & Thrombus & Outcome & Necropsy \\
\hline $\begin{array}{l}47 \\
48 \\
49 \\
50 \\
51 \\
52 \\
53 \\
54 \\
55 \\
56 \\
57 \\
58 \\
59 \\
60\end{array}$ & $\begin{array}{l}2 \cdot 7 \dagger \\
3 \cdot 3 \\
3 \cdot 0 \\
3 \cdot 5 \\
3 \cdot 0 \\
\text { Asystole } \\
3 \cdot 0 \\
2 \cdot 7 \dagger \\
5 \cdot 0 \\
\text { Asystole } \\
\text { Asystole } \\
3 \cdot 0 \\
3 \cdot 2 \\
3 \cdot 0\end{array}$ & $\begin{array}{l}38 \\
47 \cdot 5 \\
49 \cdot 5 \\
28 \\
48 \\
- \\
50 \\
42 \cdot 5 \\
49 \\
- \\
- \\
43 \cdot 5 \\
34 \cdot 5 \\
39\end{array}$ & $\begin{array}{l}\text { Yes } \\
\text { Yes } \\
\text { Yes } \\
\text { Yes } \\
\text { Yes } \\
- \\
\text { Yes } \\
\text { No } \\
\text { Yes } \\
- \\
\bar{Y} \\
\text { Yes } \\
\text { Yes } \\
\text { Yes }\end{array}$ & $\begin{array}{l}\text { Yes } \\
\text { Yes } \\
\text { Yes } \\
\text { No } \\
\text { Yes } \\
\\
\text { Yes } \\
\text { No } \\
\text { Yes } \\
- \\
- \\
\text { Yes } \\
\text { Yes } \\
\text { Yes }\end{array}$ & $\begin{array}{l}\text { No } \\
\text { No } \\
\text { No } \\
\text { No } \\
\text { No } \\
\text { RA } \\
\text { No } \\
\text { RA } \\
\text { RA, LPA, RPA } \\
\text { RA, RV } \\
\text { RA } \\
\text { RA } \\
\text { RA } \\
\text { No }\end{array}$ & $\begin{array}{l}\text { Died } \\
\text { Died } \\
\text { Died } \\
\text { Died } \\
\text { Died } \\
\text { Died } \\
\text { Died } \\
\text { Alive } \\
\text { Alive } \\
\text { Died } \\
\text { Died } \\
\text { Alive } \\
\text { Alive } \\
\text { Died }\end{array}$ & $\begin{array}{l}\text { No } \\
\text { No } \\
\text { Yes; multiple emboli. } \\
\text { No } \\
\text { Yes; multiple emboli. } \\
\text { Yes; multiple emboli. } \\
\text { No } \\
- \\
\text { - } \\
\text { No } \\
\text { Yes; no lung emboli. } \\
\text { Yes; mutiple emboli. }\end{array}$ \\
\hline
\end{tabular}

LPA, left pulmonary artery; RPA, right pulmonary artery. RA, right atrium; RVEDD, right ventricular end diastolic diameter (a normal RVEDD is < 27 mm); VCI,

Four of these seven patients recovered after operation or thrombolytic therapy; three died. Necropsy was performed in two patients and showed multiple lung emboli in one. In the second patient in whom acute cardiorespiratory collapse associated with asystole developed 3 days after operation for an abdominal aortic aneurysm, a large right atrial thrombus was noted at echocardiography (performed during a failed attempt at resuscitation). The thrombus was confirmed at necropsy. No emboli were found in the pulmonary arterial tree. However, there was evidence of a fresh, extensive left ventricular infarction and this was judged to be the cause of death.

All of the seven patients in whom no thrombi were seen died despite therapy. A necropsy was performed in only three, and multiple lung emboli were demonstrated in all of them.

\section{FOLLOW UP ECHOCARDIOGRAPHY}

Twenty five patients had at least one echocardiographic examination more than 0.5 months after the initial study (range $0.5-60$ months). Of these, 19 patients (76\%) showed improvement in their abnormal echocardiographic indices (table 3 ). The earliest variable to return to normal was the collapse index of the inferior vena cava (normal in all 19 patients). Reduction of the peak velocity or grade of tricuspid valve regurgitation was the next index to show improvement (no regurgitation detected in five patients and reduced velocity or grade of regurgitation in 12 patients). The right ventricular end diastolic dimension and interventricular septal motion became normal in 13 patients; in six others the right ventricular dimensions diminished, but all had persistent abnormalities of septal motion.

Six patients showed no change in any of the measured indices of right ventricular function (follow up interval $2 \cdot 5-26$ months).

\section{Discussion}

The outcome in patients with major emboli depends on the rapidity with which the correct diagnosis is established and appropriate treatment started. Whereas several risk factors for pulmonary embolism have been recognised, the clinical syndromes associated with embolism are varied and mimic other illnesses. All patients in this series had presenting features suggestive of massive (acute or subacute) pulmonary embolism. This may reflect in part the referral pattern of patients to the

Table 3 Follow up echocardiography

\begin{tabular}{|c|c|c|c|c|c|c|}
\hline No & $\begin{array}{l}\text { Interval } \\
\text { (mnth) }\end{array}$ & $\begin{array}{l}\text { Tricuspid regurgitation } \\
\text { peak velocity }(\mathrm{m} / \mathrm{s})\end{array}$ & $R V E D D$ & $R V$ dysfunction & $\begin{array}{l}\text { Comment } \\
V C I<40 \%\end{array}$ & \\
\hline 1 & 0.6 & None & $33 \cdot 5$ & No & No & \multirow{22}{*}{$\begin{array}{l}\text { Dilated RV, but improved function } \\
\text { Diminished grade of TR } \\
\text { No change from first echocardiogram } \\
\text { No change } \\
\text { Partial improvement in RV function } \\
\text { Partial improvement in RV function } \\
\text { No change from first echocardiogram } \\
\text { No change from first echocardiogram } \\
\text { Partial improvement in RV function } \\
\text { Partial improvement } \\
\text { No change from first echocardiogram; extensive } \\
\text { left ventricular wall motion defects }\end{array}$} \\
\hline 4 & 4 & $2 \cdot 8$ & Normal & No & No & \\
\hline 6 & 0.3 & $2 \cdot 3$ & Normal & No & No & \\
\hline 7 & 9 & None & Normal & No & No & \\
\hline 10 & 7 & $2 \cdot 5$ & Normal & No & No & \\
\hline 11 & 36 & & & No & No & \\
\hline 12 & 60 & $2 \cdot 0$ & Normal & No & No & \\
\hline 13 & 45 & $2 \cdot 3$ & Normal & No & No & \\
\hline 14 & 1 & None & Normal & No & No & \\
\hline 17 & 13 & 3.6 & $49 \cdot 5$ & Yes & Yes & \\
\hline 18 & 17 & None & Normal & No & No & \\
\hline 19 & 2.5 & $3.0 t$ & 29 & Yes & Yes & \\
\hline 20 & 0.5 & 3.0 & 33 & Yes & No & \\
\hline 22 & 48 & $3 \cdot 2$ & 31.5 & Yes & No & \\
\hline 25 & 15 & $3 \cdot 3$ & 38 & Yes & Yes & \\
\hline 28 & 5 & $3 \cdot 2$ & $34 \cdot 5$ & Yes & Yes & \\
\hline 29 & 2 & None & Normal & No & No & \\
\hline 32 & $0 \cdot 5$ & 2.9 & Normal & No & No & \\
\hline $\begin{array}{l}35 \\
36\end{array}$ & $\begin{array}{r}12 \\
0.5\end{array}$ & $\begin{array}{l}\text { None } \\
3.0\end{array}$ & $\begin{array}{l}\text { Normal } \\
29 \cdot 5\end{array}$ & $\begin{array}{l}\text { No } \\
\text { Yes }\end{array}$ & $\begin{array}{l}\text { No } \\
\text { No }\end{array}$ & \\
\hline 39 & 2 & 3.1 & 42 & Yes & No & \\
\hline 40 & 21 & $3 \cdot 2$ & 45 & Yes & Yes & \\
\hline 41 & & $2 \cdot 8$ & Normal & No & No & \\
\hline 42 & 0.5 & 3.0 & Normal & No & No & \\
\hline 55 & 26 & $4 \cdot 6$ & $46 \cdot 5$ & Yes & Yes & Severe persistent pulmonary hypertension. \\
\hline
\end{tabular}

TR tricuspid requrgitation; RA, right atrium; RVEDD, right ventricular end diastolic diameter (a normal RVEDD is $<27 \mathrm{~mm}$ ); VCI, collapse index of inferior vena TR, tricuspid regurgitation; RA, right atrium; RVED, right ventricular end diastolic diameter 3 or grade 4 regurgitation on Doppler colour flow imaging. LPA, left pulmonary artery; RPA, right pulmonary artery. 
cardiologist. Though this was a consecutive series it is possible that in patients with less severe pulmonary embolism (and presumably without raised pulmonary arterial pressure) were not referred.

Most emboli originate from thrombi in the venous system of the legs, and deep vein thrombosis is often clinically silent. The diagnosis of pulmonary embolism has evolved from the use of techniques to identify the presence of deep venous thromboses in the legs to demonstration of areas of the lung fields that are not perfused but are ventilated (ventilation-perfusion scan), and finally to confirm directly the presence and extent of vascular occlusion by selective pulmonary arterial angiography.

The ventilation-perfusion scan has a considerably error rate when compared with angiography. In a correlative study, Marsh et al showed pulmonary emboli by angiography in $33 \%$ of patients with a low probability scan. ${ }^{5}$ Conversely, $55 \%$ of patients with a high probability scan had no emboli. A more recent study of the diagnostic value of ventilation-perfusion scans also confirmed that high probability scans have a low sensitivity for diagnosing pulmonary emboli. ${ }^{20}$ Angiography, while very sensitive for embolism is an expensive, invasive investigation that carries a small but definite risk of serious complications. Until better indices for suspicion of pulmonary embolism are established, pulmonary angiography will be performed unnecessarily in some patients. ${ }^{67}$

\section{ECHOCARDIOGRAPHY}

The widespread availability of high resolution cross sectional echocardiography means that this technique can be used for direct visualisation of thrombi in the right side of the circulation and to exclude structural cardiac defects or cardiomyopathy. Though direct visualisation of thrombi in the pulmonary arteries is diagnostic of embolism such thrombi are detected by surface echocardiography in only a few patients. Only 10 patients in this series showed evidence of thrombi in the right side of the circulation, and in one case this was probably secondary to an extensive myocardial infarction and ventricular standstill. Transoesophageal echocardiography has improved the detection of central pulmonary arterial emboli. ${ }^{21}$ Peripheral emboli will, however, be missed, and in patients in an unstable haemodynamic state the procedure may be safely performed only after endotracheal intubation and mechanical ventilation. Acute right ventricular dilatation and dysfunction could, however, be easily recognised by measurement of the right ventricular end diastolic diameter and qualitative assessment of the motion of the interventricular septum in diastole; both served as indirect indices of embolism. In a study of patients with confirmed emboli Kasper et al showed right ventricular and pulmonary arterial dilatation and leftward shift of the interventricular septum in diastole. ${ }^{8}$ Paradoxical septal bulging in diastole occurs as a consequence of both right ventricular dilatation and simultaneous reduction in left ventricular preload caused by pulmonary embolism, which decreased the left to right ventricular diastolic pressure gradient. ${ }^{19}$ Paradoxical bulging of the interventricular septum may be a useful sign even in patients with asystole undergoing resuscitation, because in the unloaded non-beating heart the septum normally occupies a central position between the two ventricles. ${ }^{22}$ Clinical improvement coincides with a decrease in the mean systolic pulmonary arterial pressure and restoration of the normal configuration of the interventricular septum. ${ }^{11}$

Continuous wave Doppler ultrasound can be used to estimate right ventricular systolic pressure from the peak velocity of tricuspid regurgitation..$^{10}$ The systolic pulmonary artery pressure may thus be calculated, even without taking into account the mean right atrial pressure. ${ }^{23}$ Tricuspid regurgitation often accompanied acute pulmonary embolism, occurring in $99 \%$ of patients with effective right ventricular contraction. Cardiac catheterisation data suggest that the mean pulmonary arterial pressure correlates with the angiographic severity of embolism. ${ }^{24}$ Though the mean pressure can be derived from the Doppler velocity profile, the peak velocity alone served as a sensitive indicator of raised pulmonary arterial pressure. The finding of raised right ventricular systolic pressure in combination with dilatation of the right ventricle may also distinguish pulmonary embolism from right ventricular infarction-in which the peak velocity of tricuspid regurgitation may be expected to be low. There seemed to be no relation between the peak systolic pressure and the clinical outcome. Alterations in the peak velocity or grade of tricuspid regurgitation, however, accompanied improvements in other indices of right ventricular function.

It has been suggested that in patients with pulmonary embolism a more specific sign of decreased right ventricular reserve may be an increase in the filling pressure. ${ }^{25}$ Changes in the mean right atrial pressure were studied by calculation of the collapse index of the inferior vena cava. The diameter of the inferior vena cava changes with alterations in central venous pressure or volume. Additional changes occur during the respiratory cycle, reflecting alterations in intrathoracic pressure and consequently venous return to the lungs. Acute obstruction of the pulmonary circulation and the concomitant reduction in right ventricular compliance limit the normal augmentation of venous return with inspiration and may therefore be expected to blunt this variation in diameter with respiration. A reduction of the collapse index to $<40 \%$ has been shown to correlate strongly with a mean right atrial pressure of $>8 \mathrm{~mm} \mathrm{Hg} \cdot{ }^{12}{ }^{13} \mathrm{At}$ follow up, this index was the first to return to normal. This early return to normal may be related in part to dissolution of thrombi after treatment.

An important finding at follow up was the persistence of right ventricular dysfunction and raised pulmonary arterial pressures in 
some patients, suggesting that not all lung emboli resolve despite early and appropriate therapy, and a small proportion of patients develop chronic thromboembolic pulmonary hypertension. Such patients may develop parenchymal scarring resulting in a clinical picture of restrictive lung disease. ${ }^{26}$

In all cases structural left heart lesions could be excluded. Even in patients with a previous history of ischaemic heart disease and impaired regional left ventricular function (five patients) or cardiomyopathy (one patient), a high probability of acute pulmonary embolism could be established using the combination of the echocardiographic indices described.

\section{LIMITATIONS}

Patient selection may have played a part in the high incidence of positive echocardiographic studies in this consecutive series of patients. It is possible that patients with minor pulmonary embolism were not referred to the cardiologist for assessment. This needs to be borne in mind before these techniques are applied to patients who are less ill.

In the absence of visible thrombi in the pulmonary circulation, patients with chronic lung disease can show similar echocardiographic abnormalities of right ventricular function. Though patients with longstanding pulmonary hypertension may have an increase in right ventricular free wall thickness, ${ }^{27}$ this cannot often be accurately measured by echocardiography. In such cases only the clinical history and duration of symptoms may allow the distinction to be made. Additionally, when patients with known pulmonary disease present with signs or symptoms of pulmonary embolism, echocardiography may not be helpful. Another drawback of the study was that not all survivors had serial follow up echocardiography. It was not possible from the limited follow up data to determine the time course for resolution of right atrial and pulmonary arterial hypertension or the restoration of normal right ventricular diameter and function. Finally, not all patients underwent pulmonary angiography and it may be argued that some of them did not have pulmonary embolism. Necropsy studies could not be obtained in all patients who died in hospital and in whom additional confirmatory tests for pulmonary embolism were not performed. Despite such limitations, this study shows that echocardiography accurately detected right ventricular overload and could be used to guide clinical decision-making in the acutely ill patient.

\section{CONCLUSIONS}

Our observations support the use of cross sectional Doppler echocardiography as an initial investigative tool in patients in whom a pulmonary embolus is suspected. The indices described can be measured with ease, enabling either appropriate confirmatory investigations to be performed or, in patients with severe haemodynamic instability, thrombolytic therapy to be started without delay.
1 McNeil BJ. Ventilation-perfusion studies and the diagnosis of pulmonary embolism: concise communication. $\mathscr{f} \mathrm{Nucl}$ Med 1980;21:319-23.

2 Cheely R, McCartney WH, Perry JR, Delany DJ, Bustad $\mathrm{L}$ Wynia VH, et al. The role of noninvasive tests versus pulmonary angiography in the diagnosis of pulmonary embolism. Am $₹$ Med 1981;70:17-22.

3 Hull RD, Hirsh J, Carter CJ, Raskob GE, Gill GJ, Jay RM, et al. Diagnostic value of ventilation-perfusion lung scanning in patients with suspected pulmonary embolism. ning in patients with
Chest $1985 ; 88: 819-28$.

4 Braun SD, Newman GE, Ford K, Miller GA, Coleman RE, Dunnick NR. Ventilation-perfusion scanning and pulmonary angiography: Correlation in clinical highpulmonary angiography: Correlation in clinical high-
probability pulmonary embolism. $A F R \quad 1984 ; 143$ 977-80.

5 Marsh JD, Glynn M, Torman HA. Pulmonary angiography. Application in a new spectrum of patients. $A m$

Med 1983;75:763-70.
6 Robin ED. Overdiagnosis and overtreatment of pulmonary embolism: The emperor may have no clothes. Ann Intern Med 1977;87:775-81.

7 Menzoian JO, Williams LF. Is pulmonary angiography essential for the diagnosis of acute pulmonary embolism? Am $\mathcal{F}$ Surg 1979;137:543-8.

8 Kasper W, Meinertz T, Henkel B, Eisner D, Haahn K, Hofmann $\mathrm{T}$, et al. Echocardiographic findings in patients with proven pulmonary embolism. Am Heart $\mathcal{f}$ 1986;112:1284-90.

9 Weill F, Maurat P. The sign of the vena cava: echotomographic illustration of right cardiac insufficiency. $\mathcal{F}$ Clin Ultrasound 1974;2:27-32.

10 Yock PG, Popp RL. Noninvasive estimation of right ventricular sytolic pressure by Doppler ultrasound in patients with tricuspid regurgitation. Circulation 1984;70:657-62.

11 Jardin F, Dubourg O, Gueret P, Delorme G, Bourdarias J-P. Quantitative two-dimensional echocardiography in massive pulmonary embolism: emphasis on ventricular interdependence and leftward septal displacement. $\mathcal{f} \mathrm{Am}$ Coll Cardiol 1987;10:1201-6.

12 Cheriex EC, Leunissen KML, Janssen JHA, Mooy JMV, Van Hooff JP. Echography of the inferior vena cava is a simple and reliable tool for the estimation of dry weight in hemodialysis patients. Nephrol Dial Transpl 1989;4: 563-8.

13 Moreno FLL, Hagan AD, Holmen JR, Pryor TA, Strickland RD, Castle CH. Evaluation of size and dynamics of the inferior vena cava as an index of righ sided cardiac function. Am 7 Cardiol 1984;53:579-85.

14 Omoto $R$. Real-time intracardiac blood flow imaging with color coded two-dimensional Doppler technique: clinical significance of 2-D Doppler. Kokyu To funkan 984;32:217-25.

15 Cheriex EC, Lambregts H, Pieters F, Brugada P. Is tricuspid regurgitation underestimated as a clinical problem in valvular heart disease? In: Erbel $R$, ed. Transesophageal echocardiography. Berlin: Springer-Verlag, 1989:77-88.

16 Goldhaber SZ, Braunwald E. Pulmonary embolism. In: Braunwald E, ed. Heart disease. Philadelphia: WB Saunders, 1992:1558-80.

17 Miller GAH, Sutton GC, Kerr IH, Gibson RV, Honey M. Comparison of streptokinase and heparin in treatment of isolated acute massive pulmonary embolism. $\mathrm{Br} \mathrm{Med} \mathcal{F}$ $1971 ;$ ii:681-4.

18 Feigenbaum $H$. Echocardiographic measurements and normal values. In: Feigenbaum $\mathrm{H}$, ed. Echocardiography. Philadelphia: Lea \& Febiger, 1986:622.

19 Guzman PA, Maughan WL, Yin FCP, Eaton LW, Brinker JA, Weisfeldt ML, Weiss JL. Transseptal pressure gradient with leftward septal displacement during the Mueller manoeuver in man. Br Heart $¥ 1981 ; 46: 657-62$.

20 The PIOPED Investigators: Value of the ventilation/perfusion scan in acute pulmonary embolism: Results of the prospective investigation of pulmonary embolism diagprospective investigation of pulmonary em
nosis (PIOPED). $\mathscr{f} A M A$ 1990;263:2753-9.

21 Wittlich N, Erbel R, Eichler A, Schuster S, Jakob H, Iversen $\mathrm{S}$, et al. Detection of central pulmonary artery Iversen $\mathrm{S}$, et al. Detection of central pulmonary artery thromboemboli by transesophageal echocardiography in patients with severe pulmo
Echocardiogr 1992;5:515-24.

22 Lima JAC, Guzman PA, Yin FCP, Brawley RK, Humphrey L, Traill TA, et al. Septal geometry in the unloaded living human heart. Circulation 1986;74: 463-8.

23 Berger M, Haimowitz A, Van Tosh A, Berdoff RL, Goldberg E. Quantitative assessment of pulmonary hypertension in patients with tricuspid regurgitation using continuous wave Doppler ultrasound. $\mathcal{F} \mathrm{Am} \mathrm{Coll}$ Cardiol 1985;6:359-65.

24 Miller GAM, Sutton GC. Acute massive pulmonary embolism. Clinical and haemodynamic findings in 23 patients studied by cardiac catheterization and pulmonary angiography. Br Heart $\mathcal{f} 1970 ; 342: 518-23$.

25 McIntyre KM, Sasahara AA. The hemodynamic response to pulmonary embolism in patients without prior
cardiopulmonary disease. Am $\mathcal{f}$ Cardiol 1971;28: 288-94.

26 Morris TA, Ysrael MZ, Olson LK, Auger WR, Fedullo PF, Moser KM. The restrictive spirometric defect in patients with chronic pulmonary thrombo-embolic pulmonary hypertension [abstr]. Chest 1992;102:1205.

27 Come PC. Echocardiographic recognition of pulmonary arterial diseases and determination of its cause. $\mathrm{Am} \mathcal{F}$ 